\title{
FELIPE II Y SU MENTALIDAD REFORMADORA EN EL CONCILIO PROVINCIAL TOLEDANO DE 1565
}

\author{
POR \\ Ángel Pernández Collado \\ Universidad de Castilla La Mancha
}

\section{RESUMEN}

Felipe Il fue un gran impulsor en España de la doctrina y los decretos refornadores del concilio de Trento. Un cauce específico para su aplicación fueron los concilios provinciales. La provincia eclesiástica de Tolodo celebra muy pronto un concilio provincial, el affo 1565. En su preparación, convocatoria, celebración y elaboración de sus decretos refornadores el Rey Católico intervinu activamente, de forma personal y a través del representante real, dejándonos una panorámica de su mentalidad en materia oclesiástica y de su intervención en la marcha de la Iglesia en la España del siglo XVI.

\section{Abstract}

Philippe II impelled the introduction of Trento reformed decrets in Spain. A specific way for that were the provincial concilies. Toledo ecclesiastic province celebrated a concile soon, in 1565 . In its preparation and works, the Catholic King took part of it personally and through his delegate.

Felipe II fue el gran impulsor de la reforma del concilio de Trento en España. Convencido de su misión en la Iglesia española como "Rey Católico", buscará que ésta entre por caminos de renovación y por ello favorecerá cualquies iniciativa en este sentido. Sin embargo, su celo y vigilancia serán constantes para que en nada se rebaje su jurisdicción real y así, aunque los objetivos o metas a conseguir en orden a lograr la reforma fuesen los mismos para el Rey

La época de Felipe II y los Austrias Hispania Sacra 50 (1998) 
y para el Papa, los caminos o métodos elegidos por Felipe II serán diversos, reflejando una mentalidad distinta y a veces enfrentada con la Sede Apostólica. Un ejemplo concreto de esta realidad van a ser los concilios provinciales ${ }^{1}$ impulsados en España por Felipe II y, en concreto, su toma de posición en la elaboración de los cánones del concilio provincial toledano de 1565, a través de su representante real en él, don Francisco de Toledo.

\section{CONCILIOS PROVINCIALES.}

El concilio de Trento, en su sesión XXIV, decreto $2^{a}$, consiguió recuperar para la Iglesia Católica la celebración de los concilios provinciales y de los sínodos diocesanos, mandando que en cada provincia eclesiástica se celebrasen los concilios provinciales cada tres años y sínodos anuales ${ }^{2}$ en cada diócesis. Con ello se pretendía regular las costumbres, corregir los abusos, concertar las diferencias y que se adoptasen las decisiones pertinentes al momento eclesial de acuerdo con los sagrados cánones. En definitiva, se marcaba un medio de autorrevisión periódica y de reforma, tendente a vitalizar la vida de la Iglesia. Felipe II, una vez que hubo recibido el concilio de Trento en España, el 12 de julio de $1564^{3}$, se preocupó de impulsar la celebración de los concilios provinciales en su reino y de que todos contasen con una normativa básica y común.

\section{ENCUESTA Y REFLEXIONES PREVIAS.}

Con el fin de actuar lo más correcta y eficazmente posible, siempre conforme a derecho, Felipe II mandó que se enviase a los arzobispos y obispos de

1 I. PÉREZ DE HEREDIA Y VALLE, El concilio provincial de Granada de 1565. Edición crítica del malogrado concilio del arzobispo Guerrero, Roma 1990. A. MARíN OCETE, El concilio provincial de Granada de 1565: Archivo Teológico Granadino 25 (1962) 23-178. J. GoÑ GAZTAMBIDE, El concilio provincial de Tarragona de 1564-65: Archivo Tcológico Granadino 58 (1995) 23-94. E. RODRIGUEZ AMAYA, El concilio provincial de Salamanca de I565 y sus repercusiones en Plasencia: Revista de Estudios Extremeños 7 (1951) 235-295. A. FERNÁNDEZ COLlADO, Concilios Toledanos Postridentinos, Toledo, Diputación Provincial, (1996).

2 Concilio de Trento, sesión XXIV (1 1 noviembre 1563), Decretum de reformatione c. 2 (edición del texto latimo en COD 761). HeFELE-LECLERC, Histoire des conciles, X, París 1938, 508.

3 "Aceptamos y recibimos el dicho sacrosanto concilio y queremos que en estos nuestros reinos sea guardado, cumplido y ejecutado": J. TEJADA Y RAMIRO, Colección de cánones y de todos los concilios de la Iglesia en España y América, IV, Madrid 1849-55, 1. B. LLORCA, Aceptación en España de los decretos del concilio de Trento: Estudios Eclesiásticos 39 (1964) 341-360. G. MARTíNEZ DiEZ, Del decreto tridentino sobre los concilios provinciales a las conferencias episcopales: Hispania Sacra 16 (1963) 249-263. ARChIVO GENERAL DE SIMANCAS, Estado 148, 137.

La época de Felipe Il y los Austrias

Hispania Sacra 50 (1998) 
su Consejo un sustancioso cuestionario sobre el tema. Se les pedía orientación sobre quién debía convocar el concilio, cómo debía hacerse la convocatoria, qué personas debían participar en él y en qué grado, el tiempo mejor para celebrarlo, el lugar y la forma concreta de organización interna, las materias que debían tratarse y la forma de ejecutar y cumplir lo decretado 4 . Las respuestas, amplias y fundamentalmente coincidentes, no se hicieron esperar. Se han conservado las de los obispos de Valencia, Compostela y Segovia ${ }^{5}$. Posteriormente, se envió una "Instrucción" de consulta a diversas personas significativas y eruditas del Reino con el fin de reafirmar lo ya decidido y de establecer para todos unos criterios comunes para la convocatoria, preparación y celebración de estos concilios ${ }^{6}$. Sobre la base de estas respuestas, el Consejo Real celebró, en enero de 1565, dos sesiones de reflexión con el fin de orientar al Rey Católico. De allí surgieron unos criterios comunes para la celebración de los concilios provinciales en España.

La "Instrucción" constaba de 26 preguntas de muy variada índole y de la que se nos han conservado algunas respuestas o aportaciones importantes, destacando las del maestro Juan Bautista Pérez ${ }^{7}$, canónigo obrero mayor de la Catedral de Toledo, y la del P. Juan de Mariana ${ }^{8}$, de la Compañía de Jesús.

La iniciativa la toma Felipe Il quien, el día 10 de abril de 1565, dirigió una carta a todos los Prelados de sus reinos encareciéndoles la convocatoria de un concilio provincial en sus respectivas provincias eclesiásticas. Alentados por este deseo e invitación del Rey Católico, la mayor parte de los obispos metropolitanos de España se dispusieron a celebrar concilio provincial. Así lo hicieron los de Compostela, Tarragona, Granada, Zaragoza y Valencia.

Por la archidiócesis de Toledo ${ }^{9}$ recibió la carta real el obispo de Córdoba, don Cristóbal Rojas y Sandoval, por ser el Prelado más antiguo de la provincia eclesiástica de Toledo. El sería quien firmaría, el día 10 de marzo de 1565, el decreto de convocatoria del concilio provincial toledano, al que acompañaba una carta de Su Majestad Católica. La archidiócesis de Toledo se encontraba en estos momentos en una delicada situación. Su arzobispo, don Bartolomé de

\footnotetext{
4 AGS, Estado 148, 137.

5 AGS, Estado 148, 138-140. J.L. SANTOS DiEZ, Política conciliar postridentina en España, Roma 1969, 32-35.

6 BIBliOTECA CAPITUlaR DE TOLEDO, Ms. 27-25, 71-87.

7 BCT, Ms. 27-25, 72-87.

8 BCT, Ms. 27-25, 90-97.

9 G. MARTíneZ DIEZ, "Concilios Toledanos", en Diccionario de Historia Eclesiástica en España, I, Madrid 1972, 566-573. P. GuERrero VENTAS, Concilios y sinodos de Toledo, Toledo 1987. J. SÁNCHEZ HERRERO, Concilios provinciales y sínodos toledanos en los siglos XIV y XV, Universidad de La Laguna 1976. A. FERNÁNDEZ COLLADO, El concilio provincial toledano de 1582: Anthológica Annua 41 (1994) 103-252.
} 
Carranza, se encontraba fuera de la diócesis e impedido físicamente de acudir a ella por haber sido encarcelado e inmerso en un proceso contra él por parte de la Inquisición española. En 1567 sería trasladado a Roma. En su ausencia, la diócesis era regida con autoridad en lo material y espiritual por un Gobernador Eclesiástico, don Gómez Tello Girón, quien, lo mismo que el Cabildo Primado, no va a acoger con entusiasmo la convocatoria del concilio provincial, al contrario, presentarán enseguida sus quejas al rey Felipe II y sus razones para revocar su celebración ${ }^{10}$.

El concilio provincial toledano de 1565 celebró tres sesiones solemnes en la Catedral de Toledo ${ }^{11}$. La primera, el 8 de septiembre de 1565 ; en ella se tuvo la ceremonia oficial de apertura, se recibió oficialmente la doctrina del concilio de Trento, se leyeron los cánones referentes a la celebración de los concilios provinciales y sínodos diocesanos, se recitó la profesión de fe y se indicó la manera de proceder en adelante, señalando el lugat de las congregaciones, los días en que se celebrarían y otras formalidades. La segunda sesión se celebró el 13 de enero de 1566; en ella se aprobaron 31 decretos de reforma sobre obispos, clérigos, canónigos, y beneficiados, urgiendo especialmente la residencia, la moderación en el lujo y la represión de la simonía. La tercera sesión se celebró el 25 de marzo de 1566; en ella se aprobaron 28 decretos de reforma sobre cabildos, parroquias y beneficios; se clausuró solemnemente y se pidió autorización a Felipe II para imprimirlo y llevarlo a las diócesis.

El Concilio fue presidido por don Cristóbal Rojas y Sandoval, obispo de Córdoba, como sufragáneo más antiguo en la provincia eclesiástica de Toledo. Asistieron al mismo: don Pedro de la Gasca, obispo de Sigüenza; don Bernardo de Fresneda, obispo de Cuenca; don Diego de Covarrubias y Leyva, obispo de Segovia; don Cristóbal Femández de Valtodano, obispo de Palencia; don Honorato Juan, obispo de Osma; y don Diego Avila y Zúñiga, abad de Alcalá la Real (Jaén). Como representante real estuvo presente don Francisco de Toledo.

El contenido temático del concilio provocó fuertes reacciones entre los miembros de algunos cabildos de la provincia eclesiástica. Felipe II y el nuncio en España, Monseñor Rossano, se vieron obligados a intervenir en el pro-

10 BCT, Ms. 27-25, 101-103. TEjAdA, Cánones..., V, 221-223. AGS, Patronato Real 22, 37-40. ARChIVO CAPITUlAR DE TOLEDO, Actas Capitulares 12 (1563-1567) 170-207.

11 BCT, Ms. 27-25, 71-148. CONGREGACIÓN DEL CONCILIO, ROMA: Toledo-90, 1-38. AGS, Patronato Real 22, 1-114. ARCHIVO NACIONAL, MADRID: Ms. 10.338, 196-206. BIBLIOTECA Apostólica VATiCANA, RoMA: Barberini C. VI. 63; Barberini C. VI. 84; Barberini C. VI. 81 int. 2; Racc. Gen. Concilii VI. 2. J. TEJADA Y Ramiro, Colección de cánones..., V, Madrid 1855, 219-260. ACT, Actas Capitulares 12 (1563-1567) 170-300. J. SÁENZ DE AGUIRRE, Collectio maxima conciliorum omnium hispaniae, V, Roma 1693, 390-411. M. VILLANUÑo, Summa conciliorum hispaniae, III, Madrid 1785, 378-425. A. FERNÁNDEZ COLLADO, "El Concilio provincial toledano de 1565": Anthologica Annua 42 (1995) 425-613.

La epoca de Felipe II y los Austrias

Hispania Sacra 50 (1998) 
blema y, después de numerosas reuniones y encuentros entre ambas partes, se llegó a una "concordia" con los capitulares que se envió a Roma, siendo aprobada por Pío V el 27 de diciembre de 1569.

Con todo, el concilio, a pesar de las naturales y esperadas reacciones en contra de algunas personas e instituciones eclesiásticas a dejarse reformar, fue un paso decisivo en la adaptación de la legislación y espíritu de Trento a las diócesis españolas y un impulso en la vida espiritual de la diócesis toledana que iría produciendo sus frutos pasado un tiempo prudencial.

\section{CONVOCATORIA Y DIFICULTADES EN TOLEDO.}

El obispo de Córdoba, don Cristóbal Rojas y Sandoval, una vez recibida la carta real, se dispuso a dar los primeros pasos para, obedeciendo al Rey Católico, celebrar el primer concilio de la provincia eclesiástica de Toledo después de Trento. La primera medida fue hacer público el Edicto de convocatoria del concilio, fechado el día 10 de mayo de 1565 , y enviarlo a todos los prelados de la archidiócesis, cabildos, abades y a cuantas personas e instituciones comrespondía.

Acompañando al decreto de convocatoria con la intención de reforzar la fuerza del Edicto, iba también una carta que anteriormente Felipe II había dirigido al obispo de Córdoba ${ }^{12}$, fechada en Madrid el 10 de abril de 1565. En ella, Su Majestad comienza recordando el decreto del concilio de Trento referente a la celebración de los concilios provinciales y la importancia que tiene su cumplimiento para la reforma, el buen gobierno de la Iglesia y la ejecución de los decretos del tridentino. Resultando que el arzobispo de Toledo, don Bartolomé Carranza, no podía convocar y presidir personalmente el concilio provincial por hallarse preso en Roma por un proceso inquisitorial, correspondía esta misión al obispo sufragáneo más antiguo en la provincia. Por ello escribe Felipe II refiriéndose a don Cristóbal Rojas--, "cumpliendo con la obligación que tenéis y por lo que toca a vuestro cargo y ministerio, guardando lo mandado por el concilio de Trento, os encargamos convocar, juntar, y celebrar en la ciudad e iglesia de Toledo, como cabeza y metrópoli de la provincia, el referido concilio provincial. Para ello, llamaréis y juntaréis al resto de los prelados sufragáneos, a los cabildos de estas iglesias, y a las personas que conforme a los cánones antiguos y actuales deben asistir a él. Procuraréis que se proceda con la paz, la concordia y quietud que tan santo negocio y reunión requiere, y que se consiga el objetivo, fruto y efecto que se persigue, pretende y espera".

12 BCT, Ms. 27-25, 100-101. AGS, Patronato Real 22, 2. ACT, Actas Capitulares..., 179-180. 
Felipe II se compromete en la carta a prestar toda la ayuda que sea menester $y$, en cuanto el obispo de Córdoba se lo comunique, a dar las ordenes pertinentes para que los alimentos, el alojamiento y el resto de las cosas necesarias al caso estén preparadas para ayudar a conseguir la buena dirección y el buen progreso de tan santo negocio.

El 10 de abril de 1565 , Felipe II desde Madrid ${ }^{13}$, comunicaba al Gobernador General del arzobispado de Toledo, don Gómez Tello Girón, que había escrito al obispo de Córdoba, como sufragáneo más antiguo de la provincia eclesiástica, para que convocase y presidiese en Toledo un concilio provincial, conforme a lo establecido y ordenado en uno de los decretos del concilio de Trento. Con este motivo, indicaba el rey, había querido avisarle con tiempo en razón del cargo y del ministerio que ostentaba en esa Iglesia y diócesis de Toledo, con el fin de que preparase todo lo que fuera necesario para la buena dirección, desarrollo y resultado de este santo negocio. Subrayaba Felipe II que, además de hacerlo como era su obligación, esperaba recibir con su comportamiento placer y servicio por el particular cuidado y atención que pondria en el tema y por lo que entendía que importaba al servicio de Dios, nuestro Señor, y al bien de su santa Iglesia.

Ciertamente, esta comunicación no fue bien acogida ni por el Gobernador Eclesiástico, ni por el Cabildo toledano. Así lo reflejan claramente las Actas Capitulares. La convocatoria de un concilio provincial en su catedral y en la diócesis sobre el cual no habían sido consultados, la ausencia de su Arzobispo perseguido por la Inquisición, la adjudicación real de la presidencia en favor del obispo de Córdoba, y el temor de la promulgación de unos decretos conciliares que se verían obligados a cumplir, les hizo ponerse en guardia y plantearse la posibilidad, si la convocatoria del concilio seguía adelante, de bloquearle no asistiendo a él14. La polémica sería zanjada, después de tres meses de tensión, por el propio Felipe II, quien mandó al cabildo que sin excusa ni dilación debía elegir sus procuradores para el concilio, y al Gobernador Eclesiástico que les enderezara y encaminase, recordándole también que debía pagar con los dineros de la mesa arzobispal todos los gastos de los oficiales y de las otras cosas necesarias para el funcionamiento del concilio, como lo hubiera hecho el arzobispo si hubiera estado presente.

El cabildo de Toledo, nada mas conocer el anuncio de la celebración del concilio provincial, reunido capitularmente, decidió enviar dos canónigos a la Corte con una carta para el Rey Católico en la que le manifestaban sus criterios para pedirle la supresión o el retraso de la celebración del concilio ${ }^{15}$. La razón

13 AGS, Patronato Real 22, 2.

14 AGS, Patronato Real 22, 18.

IS BCT, Ms. 27-25, 102-103; ACT, Actas Capitulares..., 172-174.

La época de Felipe II y los Austrias

Hispania Sacra 50 (1998) 
principal para manifestarse en contra de la decisión real era que la diócesis se encontraba de hecho sin su arzobispo, hecho que influiría sin duda negativamente en el desarrollo de las sesiones conciliares no habiendo una cabeza de gran autoridad que aunase los intereses particulares de los obispos sufragáneos y que propiciaría que no se resolviesen muchos de los asuntos pendientes porque había algunos obispos interesados o inmersos en ellos. Además de que la imagen de Toledo, tan venerada desde siglos por sus concilios, quedaría muy dafiada si se celebrase ahora un concilio estando su arzobispo preso en la cárcel por la Inquisición.

Felipe II recibió inmediatamente a los canónigos toledanos y, después de leer la carta, les mandó regresar a Toledo y ser portadores de una carta suya al Cabildo ${ }^{16}$, fechada el día 20 de mayo. En ella, Felipe II respondía a sus razonamientos e insistía en que debía celebrarse el concilio provincial en la ciudad de Toledo, a pesar de la ausencia en ella de su arzobispo. Su Majestad indicaba que había tenido siempre mucho cuidado en lo tocante a la autoridad, decretos y preeminencia de la iglesia de Toledo, y que la convocatoria del concilio no la disminuiría en nada, a pesar del impedimento que había en la persona del arzobispo. Por tanto, señala el Rey Católico, "la cual celebración no se puede ni conviene diferir. Y así... os encargamos que pues el concilio se ha de celebrar en esa ciudad, que además de las personas que por ese Capítulo han de intervenir en el dicho concilio, vosotros, en todo lo que ocurriere y os pareciere, ayudéis y encaminéis lo que a la buena dirección y progreso del dicho concilio conviniere, como esperamos que iglesia tan principal y personas del celo y prudencia que vosotros sois, lo haréis, siendo como es tan santo negocio y tan enderezado al servicio de Dios y de su iglesia, que en ello nos haréis mucho placer y servicio"17.

A pesar de esta carta, las relaciones de Felipe II con el Cabildo siguieron tensas. Acercándose la fecha de la apertura del concilio, y después de haber hablado con don Pedro Pacheco, canónigo limosnero comisionado por el cabildo para hablar del tema con Su Majestad, el Rey Católico ${ }^{18}$ se vió obligado a exigir a los canónigos que recibiesen de buena voluntad a los obispos y a los procuradores de las diversas iglesias y cabildos sufragáneos, y que colaborasen en la búsqueda de alojamientos dignos: "Y vosotros ayudaréis en ello; y así esperamos que se dispondrá de modo que sin inconveniente ni ocasión de agravio se hará lo que deseamos y queremos cerca del dicho aposento y quedaremos de ello muy servido"19. Indica Felipe II que había escrito también al

16 BCT, Ms. 27-25, 101-102. ACT, Actas Capitulares..., 181. TEJADA, Cánones..., 221.

17 Ibidem.

18 TEJADA, Cánones..., 221.

19 Ibidem. 
Gobernador Eclesiástico del arzobispado y al Corregidor de la ciudad para que ellos diesen las ordenes pertinentes de manera que los Prelados y el resto de las personas que debían acudir al concilio fuesen bien acogidos y aposentados, usando a tal efecto los medios que estimasen oportunos. Con el fin de suavizar los términos expresados e incitar a una respuesta positiva, Felipe II hace presente el reconocimiento de que ellos poseen un oficio justo y piadoso, como es el de acoger y hospedar, y que está seguro que lo realizarán con tal cuidado que no harán siquiera mención a la dignidad y exención que en algún momento habían exigido.

Sin embargo, el 18 de julio de 1565, Felipe II se vió de nuevo obligado a escribir con cierta dureza al cabildo de Toledo ${ }^{20}$. Hasta él habían llegado noticias de que el cabildo toledano se negaba a aceptar algunos decretos del concilio de Trento referentes a la reforma de los eclesiásticos que, según ellos, debían ser revocados o moderados, y que se estaban dando pasos para apelar y solicitar a Su Santidad que los aclarase, los interpretase, y que revocase algunos de ellos. Por todos era conocido que el Rey Católico había aceptado y recibido en España el concilio de Trento y mandado cumplir. Por ello, ahora Felipe II en su carta, mandaba y encargaba al cabildo toledano que retirasen sus pretensiones a tal efecto, que en nada contravenían a sus privilegios, y que cumpliesen lo mandado y lo referido a ellos directamente por los obispos, a los cuales él daba y daría su favor y ayuda para que se ejecutasen todos los decretos del santo concilio.

A finales del mes de agosto, el día 29, el rey escribe al obispo de Córdoba sobre algunos temas referentes al concilio provincial. En la carta ${ }^{21}$ vuelve a aparecer la resistencia del cabildo toledano a colaborar en la celebración del concilio y a nombrar sus procuradores en él. Por ello, le anunciaba una nueva carta al cabildo para que sin dilación y excusa nombrasen sus representantes en el concilio, y otra al Gobernador del arzobispado para que enderezase el tema y corriese con todos los gastos necesarios para la organización y celebración: "Visto lo que avisáis que los del cabildo de esa santa iglesia se habían resuelto en no querer nombrar personas que asistan en el concilio, y la color y fin con que se mueven, y la consecuencia y ejemplos que de esto se podría seguir, les escribimos lo que conviene para que, sin excusa ni dilación, nombren;... y al gobernador de ese arzobispado que lo enderece y encamine; escribimos al dicho gobernador que de dineros de esa mesa arzobispal provea los que fueren menester para gastos de oficiales y otras cosas necesarias, que estando el arzobispo presente había de prover y eran a su cargo para la celebración de ese concilio"22.

20 TEJADA, Cánones..., 220-221.

21 AGS, Estado 146, 6.

22 Ibidem.

La época de Felipe II y los Austrias

Hispania Sacra 50 (1998) 


\section{ELECCIÓN DEL REPRESENTANTE REAL.}

Según costumbre inmemorial practicada en los concilios celebrados en España, los reyes estaban presentes en ellos o enviaban sus representantes. Felipe II, al impulsar la celebración del concilio provincial de Toledo comenz $\delta$ a pensar en la persona que pudiese representarlo de forma adecuada y digna, estimando, según escribirá después de realizada ya la elección del embajador real, que "no es necesaria nuestra asistencia personal en ese concilio, con esto se puede conseguir el mismo efecto, además de que nuestras muchas y grandes ocupaciones lo impiden"23. Esta práctica común en España no contaba con el respaldo de Roma, donde no entendían la presencia del rey o de sus representantes en una reunión de eclesiásticos, como lo era un concilio. Si en este concilio de 1565 se consintió en permitir esta costumbre, las posturas se endurecerían al celebrarse el concilio provincial de 1582 , siendo ésta la causa principal de su retraso en recibir la aprobación pontificia.

Felipe II pensó en un primer momento en don Francisco de Vargas, personalidad excepcional, antiguo embajador real en Trento y en Roma, doctor en ambos derechos, persona de gran confianza del rey y probado defensor de las prerrogativas reales. Don Francisco en Ios meses anteriores al concilio se encontraba descansando en el Monasterio jerónimo de La Sisla, muy cerca de la ciudad de Toledo. Su inicial designación debió de despertar numerosos recelos en los sectores más cercanos a Roma a causa de su energía, independencia y regalismo radical.

En los días inminentes a la apertura del concilio, el rey se decidió por otro candidato que gozaba también de una alta dignidad y de una carrera liena de servicios a la corona española. Se trataba de don Francisco de Toledo ${ }^{24}$, mayordomo de Felipe II, hijo segundo del conde de Oropesa, hombre docto en ciencias eclesiásticas y rico en virtudes cristianas. Anteriormente había sido virrey del Perú, donde desarrolló una excelente labor organizadora, y había vivido muy cerca de Carlos $\mathrm{V}$, acompañándole incluso al Monasterio de Yuste.

El 31 de agosto de 1565, en Segovia, el rey firmaba la cédula ${ }^{25}$ por la que se nombraba a don Francisco de Toledo representante real en el concilio. El documento señalaba sucintamente las atribuciones del legado. La noticia ${ }^{26}$ fue comunicada inmediatamente a todos los interesados: obispo de Córdoba, Go-

\footnotetext{
23 Ibidem.

24 Francisco de Toledo, en "Diccionario de Historia de España", dirg. G. Bleiberg, III, Madrid 1969, 778-779. R. LeVILlJER, Don Francisco de Toledo, supremo organizador del Perú, 3 v., Madrid 1935.

25 AGS, Estado 146, 1 y 24.

26 AGS, Estado 146, 6.
} 
bernador Eclesiástico del arzobispado de Toledo, cabildo de la Catedral, corregidor, ciudad,...etc. A don Cristóbal Rojas, obispo de Córdoba y presidente del concilio, le comunicaba el Rey Católico en una carta de finales de agosto que había "nombrado a don Francisco de Toledo para que asista e intervenga por Nos y en nuestro nombre en el concilio provincial que ahí se ha de celebrar por concurrir en su persona la calidad y buenas partes que para el negocio tan grave y $\tan$ importante se requieren. Ahora le enviamos con la instrucción y advertimentos que de él entenderéis y con la orden de comunicaros todo lo que se ofreciere, y de asistiros y tener con Vos muy particular inteligencia, y la misma os encargamos que Vos tengáis con él y le creáis en todo como a Nos mismo y hagais lo que de nuestra parte os digere y pidiere, para que procediendo ambos con esta conformidad los negocios se enderecen y traigan al fin que se desea y pretende, que es principalmente a lo que conviene al servicio de Dios nuestro Señor y al buen gobiemo de las iglesias de esa provincia, y que se ejecute y cumpla lo establecido en el sacro concilio de Trento como se debe y que se remedien las cosas que de ello tuvieren necesidad"27.

Con estas palabras, Felipe II presentaba al legado regio y manifestaba lo que esperaba de él, y lo que a través de él esperaba conseguir, estando seguro de que la colaboración y confianza entre ambos sería tal que conseguirían llevar a buen término las sesiones del concilio, cumpliendo lo establecido en Trento, para mayor gloria y servicio de nuestro Señor. Don Francisco ocuparía un lugar de preferencia en las sesiones y congregaciones conciliares, situándose a la derecha del presidente y precediendo a los obispos sufragáneos.

Los obispos asistentes, aunque en algunos momentos no estuvieron de acuerdo con las opiniones y planteamientos del embajador real, sin embargo admitieron de buena gana su presencia, sus constantes consultas al rey e, incluso, elogiaron públicamente sus buenos servicios, su prudencia y discreción. Así lo expresaban al final del concilio: "con su prudencia y gran cristiandad ha ayudado mucho al buen progreso y conclusión de él, y asistido en todo como persona que entendía lo que de parte de Vuestra Majestad le había sido mandado y convenía a los negocios"28.

Una de las misiones de don Francisco de Toledo era la de mantener una corespondencia asidua con Su Majestad para informarle del desarrollo del concilio y para recibir los criterios reales sobre los temas a tratar. Se nos han conservado dos extensos memoriales ${ }^{29}$ donde Felipe II expresa su opinión sobre cuestiones esenciales del contenido temático del concilio provincial toledano, y que podemos resumir en seis apartados:

\footnotetext{
27 Ibidem.

28 AGS, Patronato Real 22, 39

29 AGS, Estado 146, 3 y 29.
} 
1. Cumplir lo decretado por el concilio de Trento. El rey no tiene reparos en exigir que se corrija lo que sea necesario con tal de conseguir esa meta y aún de llegar a exigencias mayores, como en el tema de la residencia de los obispos.

2. Fijar la doctrina en general, no pormenorizando demasiado los temas. En concreto, indica que no es conveniente que el concilio se entretenga en detalles precisos sobre la residencia de los obispos, sobre las mesas episcopales, sobre el número de platos o las características de los manjares, siendo más conveniente insistir en la templanza, en el buen ejemplo y la moderación.

3. Preocupación política en temas patrimoniales, judiciales y arancelarios. Se deben resaltar los intereses reales, el derecho consuetudinario y las disposiciones legales del reino para evitar reclamaciones y conflictos con las instituciones eclesiásticas.

4. Reforma de seglares y moralidad pública. Se debe estar muy atento para que en estos temas no se atente contra la jurisdicción real.

5. Evitar tratar termas que puedan alterar la paz y el desarrollo del concilio y que puedan servir de escándalo, como las discusiones sobre agravios de Roma por parte de los Prelados, derechos y privilegios de la Corona y diferencias jurisdiccionales entre metropolitanos y sufragáneos.

6. Sede Apostólica y Roma. Estar atentos a los criterios y decisiones que se toman y vienen desde Roma; intentar conjugar los intereses de la Sede Apostólica y de la Corona; no dejar que sean olvidados u omitidos los derechos reales en la iglesia española, resaltando, en concreto, el derecho de presentación de obispos y las cualidades de los candidatos al episcopado.

\section{MENTALIDAD REAL.}

El 13 de enero de 1566 se celebró, en la capilla mayor de la catedral prima$\mathrm{da}$, la segunda sesión solemne del concilio provincial, en donde fueron aprobados 31 decretos de reforma. Estos se fueron leyendo uno a uno por el diácono en voz alta. En ellos se insistía en la residencia de los obispos, en la necesidad de que diesen ejemplo de buenas costumbres tanto en su casa, mesa y vestido, como en su ministerio pastoral a través de las visitas, la vigilancia de las instituciones y sus oficiales, en la erección de parroquias y su mantenimiento, y en el rechazo a cualquier forma de simonía, sin olvidar la reforma de los cabildos con sus canónigos y beneficiados, de las parroquias y de los clérigos de cualquier grado y condición. 
Aunque la doctrina conciliar quedaba concretada en los decretos conciliares, éstos previamente, y a través de los informes del embajador real, habían pasado el trámite de ser examinados por el Rey Católico en su fase de redacción, recibiendo de él su apoyo o rechazo. Felipe II, a la vez que velaba por los intereses de la Iglesia, no quería ver perjudicada en nada su jurisdicción y su control sobre la Iglesia en España ${ }^{30}$. Un ejemplo concreto de esta vigilancia y control, ejercida a través del embajador real en el concilio toledano, es un amplio "Memorial de advertencias" 11 que Felipe II envía a don Francisco de Toledo cuando se estaban discutiendo los decretos de la segunda sesión conciliar. Aunque Su Majestad opina sobre cada uno de ellos, dejaremos constancia solamente de algunas de sus opiniones, en una panorámica de la sesión, subrayándolas con sus mismas palabras.

Respecto a la residencia de los obispos - decreto primero de reforma--, señala Felipe II que, "advertido por la generalidad de las palabras que se pusieron en el concilio de Trento cérca de las causas de ausencia, quedó esto de la residencia muy abierto y con ocasión larga para legitimar y justificar lo de la ausencia, así el prelado que lo pretende como el superior que lo ha de aprobar, desea (Su Majestad) en cuanto fuere posible que se estrechase"32. Y la misma idea de estrechar y concretar el decreto de Trento sobre la residencia de los obispos, lo expresa Felipe II en cuanto ésta se refiere a la presencia del obispo en su Iglesia catedral: "desea Su Majestad que el tiempo de esta residencia se alargase mas de lo contenido en el decreto de Trento, y se pusiese en mas obligación de lo que allí se pone, porque en esto no se entiende que contradiría a la mente del dicho decreto, cuyo fin e intención se cumple mejor cuanto más estrechamente esto se ordenare, y así todo lo que se pudiere a este propósito y a este fin acrescentar, sería muy conveniente y muy a satisfacción de Su Majestad"33.

En el tema de la mesa episcopal, que quedaría concretado posteriormente en el decreto tercero de esta sesión, Felipe II ve conveniente que se legisle sobre el tema, pero no que se descienda a unos detalles que pueden ser objeto de risa y mofa por parte de la gente: "En lo de las mesas de los Prelados, todo lo que se ordenare para que en ellas haya la templanza, frugalidad y buen ejemplo que conviene, y se excuse la curiosidad, delicadeza y superficialidad de manjares, es muy santo y muy justo; más el venir en particular a límitar el número de los manjares, que sean tres o cuatro,... no se podrá dejar de tratar en las mesas con indignidad y alguna irrisión; además que no siendo esto generalmente ordenado en todos los sínodos, como no lo será, vendría a hacerse

\footnotetext{
30 E. Garcia Hernan, La Curia Romana, Felipe II y Sixto V: Hispania Sacra 46 (1994) 631-649.

31 AGS, Patronato Real 22, 31.

32 Ibidem.

33 Ibidem.
} 
nota en la diferencia que habría en el uso cerca desto entre los prelados, tanto mas poniéndose pena, y que obligue in foro conscientiae, y queriéndolo extender a todos los demás clérigos. $Y$ así parece que esta es una materia en que conviene hablar en general y no venir a esta particularidad"34.

Sobre la erección y edificación de nuevas iglesias, tema que quedará plasmado en el decreto veintisiete, donde se indica que la iglesia matriz ayude con sus frutos a esta construcción y que se provea una dotación para los sacerdotes encargados de esta tarea, Felipe II indica que "la erección y edificación de nuevas iglesias en las partes y lugares donde parece necesario, es muy conveniente y lo que acerca de esto está ordenado muy santo y justo. Solo se debe advertir en lo que toca a la dote de estas iglesias y aplicación de frutos para ella, que se haga por la orden y en la forma que el derecho dispone"33.

En el informe o memorial aparece también el tema de la canonjía de Lectoral y las de aquellas canonjías que exigen para poseerlas tener grados académicos. Felipe II prefiere que la canonjía de lectoral se cubra mediante edicto público y concurso de oposición para evitar otros caminos que parecen menos justos: "En lo de la provisión de la prebenda para lección de Sagrada Escritura, ordenarse que aquella se haga por edicto está muy bien, y porque cuanto a este punto en algunas partes se ha pretendido que de consentimiento del prelado y cabildo se pueda proveer sin el dicho edicto ni oposición, a alguna persona que les parezca, a título de que es muy suficiente o muy eminente, y esto es abrir la puerta a negociaciones para defraudar tan buena forma y tan necesaria como es la de los edictos, se debe mirar si para excusar este inconveniente y para que quede del todo cerrado, convendrá añadir algunas palabras, como sería, que declarando que aliter facta provisio, quam praecedente edicto ex quavis causa quovis praetexto colore, sit nulla"36.

Respecto a las otras canonjías para graduados - decreto veintinueve-, donde se quiere que, al menos la mitad de las dignidades y canónigos sean doctores o licenciados en teología o derecho, Felipe II señala que "el decreto para que las dignidades y calongías se provean a graduados es santísimo; y, aunque se entiende bien que en las provisiones y collaciones que se hicieren en Roma se pretenderá que esto no les diga y que aquellas se pueden hacer libremente, mas en esto Su Majestad... tendrá la mano para que se guarde generalmente y aunque para este efecto y para otros fines se pudiera a mas particularidad, ha parecido mejor la forma del decreto para que se entre con mas justificación y escandalice menos, y se quiten las ocasiones que habría de impedirlo"37.

\footnotetext{
34 Ibidem.

35 Ibidem.

36 Ibidem.

37 Ibidem.
} 
El rey reconoce la verdad y la bondad del decreto tal como aparece en el borrador y, desde su óptica, percibe los posibles problemas que su aplicación podría suscitar, como de hecho sucedería y no tanto con los nombramientos que llegaban desde Roma, sino por las dificultades de aplicación en los propios cabildos. Con todo, Felipe II confiaba plenamente en la política que se estaba llevando en España, desde sus antecesores los Reyes Católicos, en cuanto al nombramiento de obispos, privilegiando el que fuesen letrados, y esperaba que la misma política pudiese impregnar el nombramiento de capitulares, aunque fuese por otros caminos complementarios: "Y, aunque en esto de los grados, como se ha advertido, convendría que se declarase que fuese en una de las Universidades de estos reinos, y no fuera de ellos, esto se podrá hacer por otra vía en general, y no meterlo en este decreto, porque como está dicho, conviene ir suavemente y no apretarlo hasta que se introduzca y funde" ${ }^{38}$.

Poco tiempo después, Felipe II contesta de nuevo a don Francisco de Toledo expresando su opinión sobre numerosos asuntos de los que se estaban discutiendo en el concilio provincial. El embajador real había solicitado orientación al monarca porque algunos prelados se habían quejado de la lentitud con que se avanzaba en los temas, porque Su Majestad tardaba en expresar su criterio y porque deseaban regresar cuanto antes a sus diócesis ${ }^{39}$. Felipe II envía sus orientaciones y, a la vez, nos ofrece un texto iluminador de su manera de pensar y obrar respecto al concilio y a la Iglesia de España de la que se siente no dueño, sino especialmente responsable, convencido de que en ningún caso se entromete en el foro interno de la Iglesia, ni la priva de su libertad, sino que colabora responsablemente en la consecución de su fin:

\footnotetext{
"Se os envia con ella una carta cerrada para los prelados y copia de ella para los prevenir en algunos puntos de que vos nos habéis advertido...; también se os envía un memorial de advertimentos de lo que aquí ocurre cerca de los decretos que nos habéis enviado y de las materias que en ellos se tocan. De este memorial miraréis la manera que habéis de usar, si se leerá a los prelados estando juntos en su congregación, o si ordenaréis que se remita a alguno o algunos de ellos, con quien lo tratéis, que esto se os remite para que vos allí lo veáis, teniendo fin a que se haga con la más decencia y más satisfacción de los prelados que fuere posible, advirtiéndoles, como por nuestra carta se les advierte y apunta, que nuestro fin e intento no es de impedirlos, ni embarcarlos, ni de quitarles la libertad y libre disposición de lo que les toca, antes ayudar y favorescer en tan santo negocio y darle toda autoridad y disponerlo de manera que cesen en la ejecución y cumplimiento de lo que se ordenare las dificultades que podrian ocurrir, y que con el zelo que tenemos a lo que tanto es del servicio de Dios y bien de su Iglesia, les vamos advirtiendo de lo que parece que para este fin es necesario, y que teniendo ellos, como tienen, esta misma intención, es muy bien que nos lo comuniquen y Nos les ayudemos y advirta-
}

38 Ibidem,

39 AGS, Patronato Real 22, 22.

La época de Felipe II y los Austrias

Hispania Sacra $50(1998)$ 
mos, que es cierto que tratándose en esta forma, se entenderá mejor lo que todos deseamos; y, sobre ese presupuesto y procediendo por este camino, procuraréis con toda buena manera y destreza que se haga lo que en los dichos advertimentos se contiene"40.

El 25 de mayo de 1566 se celebró, en la capilla mayor de la catedral de Toledo, la tercera sesión solemne del concilio provincial. En ella se aprobaron 28 decretos de reforma. La simple lectura de sus títulos nos hacen caer en la cuenta de la atención reformadora con que el concilio se acerca a temas como la parroquia, sus inmuebles y economía, la predicación y el catecismo, los cuidados pastorales, la comunión, y los diversos servicios parroquiales en los que se alienta a participar a todos, ayudando en su realización. Igualmente, a temas disciplinares referentes a los diversos clérigos, buscando su bien y la elevación del nivel de su vida en la clerecía: predicación, vida espiritual, comunión, rechazo a los concubinarios y a los que asisten a las corridas de toros, promoción de los estudios superiores, preparación científica, grados académicos, y preocupación por la erección de seminarios y por la formación que los jóvenes puedan recibir en ellos. No faltan, por supuesto, temas referidos al cabildo y a los canónigos, como una continuación de la reforma que sobre ellos se había iniciado con la aprobación de los decretos de la segunda sesión: predicación en la catedral, asistencia al coro y a los cabildos, comunión en los días señalados, funciones del doctoral, del lectoral, del penitenciario, distribuciones, raciones,..etc. y otros temas interesantes, como la creación del archivo episcopal, la insistencia en la clausura monástica o la música en las iglesias.

Mientras se celebraban las congregaciones que culminarían en la promulgación de los decretos conciliares, Su Majestad, como en ocasiones anteriores, y a través de su embajador en el concilio, don Francisco de Toledo, estaba muy al tanto de los temas que se trataban, así como de su contenido concreto. Por fortuna, ha quedado constancia de la opinión de Felipe II sobre los diferentes decretos que se estaban elaborando a través de sus cartas y memoriales. Señalamos algunas que, con sus propias palabras, nos muestran el interés que puso en que algunos decretos se redactasen según su criterio.

Ante el tema de la corrección a los laicos, de sus pecados públicos y vicios sociales, Felipe II se pone en guardia para evitar que desde la Iglesia se tocase su jurisdicción: "En lo que escribís que el obispo de Córdoba, presidente desse concilio, ha propuesto que acabado lo de la reformación de los prelados y clero, se ha de tratar de la correctión de los legos, y peccados y vicios públicos dellos, esta es una materia de consideración, y en que los prelados han tenido y tienen algunas pretensiones en perjuizio de nuestra jurisdictión real, a que no

40 AGS, Estado 146, 29. 
se les ha dado ni conviene dar lugar, especialmente en que pretenden que en los casos que tienen esse conoscimiento contra los legos, pueden proceder a captura de la persona y execución de los bienes sin invocación del brazo seglar, y que contra los amancebados y logreros y otros delitos que dicen ser mixti fori, pueden proceder haciendo procesos judiciales en forma y condenar en los cuales sean, aunque se admite que procedan por edictos y censuras, generalmente no se les da lugar a otro modo de proceder; y porque en lo susodicho y en otras cosas, queriendo tratar desta materia, se podrían entremeter haziendo sobrello decretos en perjuizio de nuestra jurisdictión y del estado seglar, estaréis muy prevenido y muy advertido quando a esta parte se llegare, para que seamos puntualmente avisado"4l.

La misma posición de Felipe II aparece en el tema de los nombramientos episcopales. Insiste el rey en que se mantenga la línea y los criterios que desde años atrás se siguen para el nombramiento de los Prelados y que tan buenos frutos estaban dando, y que désde luego se contase con su consentimiento: "En lo de los obispos titulares de anillo, en cuanto toca a la creación dellos que $\mathrm{Su}$ Santidad haze, convendría mucho que aquella no fuesse sino de las personas que tuviessen nuestro consentimiento y aprobación de uno de los metropolitanos destos reinos, o del obispo de cuya diócesis fuesse el tal promovendo, y que precediese la información de las calidades, que conforme a derecho y a los decretos desse concilio se requieren en los obispos; ... que importa mucho que el ingreso destos obispos annulares se ordene de manera que no haya la licencia y generalidad que hasta aquí ha habido. $Y$ en cuanto al uso y ejercicio de su ministerio, en que ha habido tanta desorden assí en lo de la celebración de las órdenes como en otros actos pontificales, guardándose lo dispuesto en los decretos del concilio de Trento, y lo que os habemos advertido cerca desta materia paresce que será sufficiente remedio"42.

Los temas a este respecto se multiplican y merecerían, en otro momento, un estudio comparativo de los textos según la mente de los obispos y la mente de Su Majestad, y cómo quedaron definitivamente redactados. Destacamos, como ejemplo, dos detalles que también por decisión de Felipe II, según informaba su embajador, quedaron fuera de los decretos conciliares: "En lo de los decretos del penitenciario y mayorazgos, y donaciones y décimas, se dejan de decretar, como Vuestra Majestad lo ha mandado. Y en lo de los beneficios simples servideros, se pone como Vuestra Majestad lo envió a mandar. Y las penas pecuniarias que se ponían a los clérigos en el decreto de los toros se quitan, como Vuestra Majestad lo mand 6 "43.

\footnotetext{
41 Ibidem.

42 Ibidem.

43 AGS, Patronato Real 22, 43.
} 
Con la aprobación de los decretos conciliares de la tercera sesión, aparentemente todo había terminado. Sin embargo, habían quedado temas o flecos sobre los que interesaba estar muy atentos desde el ámbito de la cancillería real, de manera que algunos de ellos fueran favorecidos y potenciados, completando así las decisiones conciliares, y sobre otros se debería estar muy atento para evitar que fuesen un escape a lo legislado, que pudiesen dañar la jurisdicción real, o que fuesen causa de enfrentamientos y de pérdida de la paz y la quietud que se deseaba para la iglesia y el reino. Por ello, don Francisco de Toledo, antes de marchar de la ciudad, notificó a Felipe II, a través de una carta ${ }^{44}$ al secretario real doctor Velasco, una serie de "Advertencias" que Su Majestad debería tener muy presentes para potenciar el concilio provincial, ahora finalizado, y para evitar problemas en la jurisdicción real. Subrayamos, como anteriormente de esta extensa carta, los aspectos que a nuestro parecer son más sobresalientes para entender el pensamiento real sobre estos temas.

Don Francisco manifiesta, en primer lugar, que había tenido siempre en el Concilio el máximo cuidado y el deseo de servir fielmente a Su Majestad cumpliendo todo lo que este le mandaba por escrito o lo que se le indicaba de pałabra, pues "cuanto en mí fue, se hizo y cumplió al pie de la letra, todo como se me manđó; y como para este efecto hice poner el concilio de Trento en romance y apuntar en cada decreto los advertimentos de las instrucciones y cartas de Su Majestad" 45 .

Si con estas líneas don Francisco nos señala su forma de actuar en lo tocante a las indicaciones de Felipe $\Pi$, no son menos elocuentes sus palabras al referirse a cómo había actuado con los obispos en el concilio, presentando el pensamiento de Su Majestad: "Y ansí en las congregaciones y acuerdos particulares, que los perlados tenían solamente, y no en las generales que se tenían con los cabildos, cuando se trataba de la materia de los decretos de Trento yo hacía mi apuntamiento con el advertimento de Su Majestad, y ansí se trataban y conferían entre mi y los perlados. Y de allí resultaba lo que yo escribía a Su Majestad y lo que Su Majestad me respondía;... se tuvo mucho respeto de servir a Su Majestad, y con mucha llaneza y a esto ayudaba mucho la bondad de los perlados que al dicho concilio asistieron" ${ }^{46}$.

Respecto a la celebración de los concilios provinciales, advierte don Francisco de Toledo que es importante que Su Majestad entienda lo mucho que aporta a la religión, al bien de la iglesia, al aumento de la cristiandad, al servicio del culto divino y a la reforma de las costumbres, el que se celebren concilios provinciales en España cada tres años, según lo manda el concilio de

44 AGS, Patronato Real 22, 37.

45 Ibidem.

46 Ibidem. 
Trento, especialmente si son presididos por metropolitanos celosos de la reforma y del bien de la Iglesia, lo cuales, con el impulso de Su Majestad y la presencia y ayuda del representante real, podrán pedir cuentas a los obispos de cómo y de qué manera han guardado, cumplido y ejecutado los decretos de Trento y los del anterior concilio provincial e, igualmente, en lo referente a las otras tareas de su ministerio y oficio pastoral.

Siguiendo con el deseo y objetivo de reformar a los obispos, don Francisco de Toledo estima que un medio que les apretaría y les obligaría a hacer las cosas como deben sería, como lo había intentado en el concilio, que los testigos sinodales nombrados en la última sesión conciliar, fuesen personas de mucho peso, los cuales con el ánimo y el favor de Su Majestad, y con la recepción de un salario a costa de los obispos y de las iglesias catedrales, estarían presentes en la próxima reunión conciliar y allí dirían, y no disimularían, la verdad sobre la vida y actuación pastoral de los obispos. Lástima, indica el embajador real en su informe, que no se haya podido asentar este particular con los obispos en la forma que convenía. Sugiere también don Francisco de Toledo, que importaría mucho para el futuro conseguir que los obispos tuviesen plena y total jurisdicción sobre los cabildos, para que así se pudiesen evitar tantos inconvenientes como continuamente se presentaban con ellos.

Un tema que se repite en diversos apartados de las "Advertencias", y siempre con preocupación, es el de la jurisdicción eclesiástica y la real, las relaciones con Roma y la documentación que emana de una y otra instancia en materia religiosa. Don Francisco de Toledo advierte a Felipe II que los obispos se quejaban continuamente de los numerosos despachos que llegaban desde Roma en favor de algunos súbditos librándoles de su jurisdicción episcopal, dándoles libertad e impidiendo que pudiesen ser castigados; igualmente, las quejas se extendian a los curiales españoles residentes en Roma, los cuales amparaban y defendían a estos súbditos frente a su poder episcopal, consiguiendo así, con la provisión de beneficios curados y otras dispensas, que sus iglesias estuviesen revueltas y desasosegadas. Y la protesta y la confusión se hacía mayor entre los obispos ante el hecho de tener que dar cuenta ante el Consejo Real de Su Majestad de cualquier documento que les llegase desde Roma. Finalmente, señala el embajador real, habría que evitar la ocasión de que algunos predicadores puedan decir libremente que la Iglesia no goza de libertad y que está oprimida. La razón de esta protesta está en que los miembros del Consejo Real retienen o impiden la publicación de algunas Bulas o despachos de Su Santidad en favor de la jurisdicción eclesiástica. 


\section{AGRADECIMIENTOS AL REY.}

Una vez que el concilio provincial hubo acabado oficialmente, los obispos, a través de don Francisco de Toledo, pidieron permiso a Felipe II para regresar a sus diócesis lo antes posible. E, igualmente, don Cristóbal Rojas Sandoval, como presidente del concilio, solicitó de Su Majestad el permiso necesario para imprimir inmediatamente las Actas conciliares ${ }^{47}$. La autorización debió darse enseguida, pues fueron impresas en Alcalá a finales del año 1566. El cabildo de Toledo, por su parte, en sesión capitular del sábado 30 de marzo, acordó solicitar a un amanuense que realizase una copia de las Actas conciliares y que se pagase a su costa ${ }^{48}$. Desgraciadamente, si se hizo, no se ha conservado esta copia en el Archivo Capitular. Felipe II solicitó y le fue entregado, a través del embajador real, una copia de las Actas con "todos los decretos juntos que en este concilio se han hecho"49. A la vez, don Francisco de Toledo le anuncia que también "había mandado ya que se sacara un traslado del libro de los actos del concilio, como Vuestra Majestad manda, y yo tendré cuenta en enviarlo"s0.

Antes de regresar a sus diócesis, los obispos participantes redactan y firman una carta ${ }^{51}$ a Felipe II, fechada el 26 de marzo de 1566, agradeciendo su ayuda en la convocatoria, desarrollo y conclusión del concilio. Los Prelados, que se declaraban en el escrito humildes capellanes y vasallos de Su Majestad, expresan a Felipe II su agradecimiento, indicando que habían procurado en todo Jo tratado satisfacer el celo de Su Majestad, que no solo había mandado convocar el concilio, sino que también había procurado que se celebrase con paz y quietud, pensando siempre en el bien de la provincia eclesiástica y en el servicio a nuestro Señor. Subrayan, igualmente, el deseo que habían puesto en acertar con sus decisiones y decretos, de manera que se pudiera conseguir el fruto que Su Majestad pretendía y, sobre todo, para que fuese servido nuestro Señor y su Iglesia sacase gran provecho de ello, puesto que de no ser así hubiera sido inútil todo el trabajo que se había realizado y que, ciertamente, había sido mucho. Terminan la carta los obispos agradeciendo la presencia, prudencia, y gran cristiandad del embajador real, don Francisco de Toledo, quién, en su nombre, les había manifestado lo que Su Majestad mandaba y lo que convenía. La carta conserva las firmas autógrafas de los seis obispos participantes y la del abad de Alcalá la Real.

\footnotetext{
47 AGS, Patronato Real 22, 43.

48 ACT, Actas Capitulares..., 258.

49 AGS, Patronato Real 22, 43.

so Ibidem.

5i AGS, Patronato Real 22, 39.
} 
En la misma fecha, 26 de marzo 1566, al día siguiente de la clausura, el obispo de Córdoba, don Cristóbal Rojas enví a Felipe II una carta personal ${ }^{52}$, además de la conjunta con el resto de los obispos, en la que le agradecía toda la ayuda e interés que había manifestado por el concilio. En el escrito destaca cuatro aspectos: 1. El concilio provincial en el que tanto interés había puesto Su Majestad había concluido felizmente con mucha solemnidad y devoción en la ciudad y catedral de Toledo. 2. Don Francisco de Toledo había realizado su oficio en el concilio conforme a quien era, en consonancia con lo que Su Majestad esperaba de él, actuando con gran virtud y paciencia, dando un excelente ejemplo. 3. El celo e interés de los obispos participantes había sido también grande, buscando siempre el servicio de nuestro Señor y de Su Majestad, el remedio de los abusos, la reforma de las costumbres y la santa celebración del culto divino. 4. Todos habían visto y entendido el gran bien y provecho que podían producir en la Iglesia los concilios provinciales; por ello suplicaba que Su Majestad siguiese fomentando su celebración en el tiempo establecido por el concilio de Trento.

52 AGS, Patronato Real 22, 38.

La época de Felipe II y los Austrias Hispania Sacra 50 (1998) 